\title{
Assessing the sensitivity of placental growth factor and soluble fms-like tyrosine kinase 1 at 36 weeks' gestation to predict small-for- gestational-age infants or late-onset preeclampsia: a prospective nested case- control study
}

Teresa M. MacDonald ${ }^{1,2,3^{*}}$ (D), Chuong Tran ${ }^{4}$, Tu'uhevaha J. Kaitu'u-Lino ${ }^{2,3}$, Shaun P. Brennecke ${ }^{2,5}$, Richard J. Hiscock ${ }^{2}$, Lisa Hui ${ }^{1,2,3}$, Kirsten M. Dane ${ }^{1}$, Anna L. Middleton ${ }^{1,2}$, Ping Cannon ${ }^{2,3}$, Susan P. Walker ${ }^{1,2,3}$ and Stephen Tong ${ }^{1,2,3}$

\begin{abstract}
Background: Fetal growth restriction is a disorder of placental dysfunction with three to four-fold increased risk of stillbirth. Fetal growth restriction has pathophysiological features in common with preeclampsia. We hypothesised that angiogenesis-related factors in maternal plasma, known to predict preeclampsia, may also detect fetal growth restriction at 36 weeks' gestation. We therefore set out to determine the diagnostic performance of soluble fms-like tyrosine kinase 1 (sFlt-1), placental growth factor (PIGF), and the sFlt-1:PIGF ratio, measured at 36 weeks' gestation, in identifying women who subsequently give birth to small-for-gestational-age (SGA; birthweight <10th centile) infants. We also aimed to validate the predictive performance of the analytes for late-onset preeclampsia in a large independent, prospective cohort.

Methods: A nested 1:2 case-control study was performed including 102 cases of SGA infants and a matched group of 207 controls; and 39 cases of preeclampsia. We determined the diagnostic performance of each angiogenesis-related factor, and of their ratio, to detect SGA infants or preeclampsia, for a predetermined 10\% false positive rate.

Results: Median plasma levels of PIGF at 36 weeks' gestation were significantly lower in women who subsequently had SGA newborns (178.5 pg/ml) compared to normal birthweight controls $(326.7 \mathrm{pg} / \mathrm{ml}, p<0.0001)$. sFlt-1 was also higher among SGA cases, but this was not significant after women with concurrent preeclampsia were excluded. The sensitivity of PIGF to predict SGA infants was $28.8 \%$ for a $10 \%$ false positive rate. The sFlt-1:PIGF ratio demonstrated better sensitivity for preeclampsia than either analyte alone, detecting $69.2 \%$ of cases for a $10 \%$ false positive rate.

Conclusions: Plasma PIGF at 36 weeks' gestation is significantly lower in women who subsequently deliver a SGA infant. While the sensitivity and specificity of PIGF currently limit clinical translation, our findings support a blood-based biomarker approach to detect late-onset fetal growth restriction. Thirty-six week sFlt-1:PIGF ratio predicts $69.2 \%$ of preeclampsia cases, and could be a useful screening test to triage antenatal surveillance.
\end{abstract}

Keywords: Biomarker, Fetal growth restriction, Late-onset, Placental growth factor, Preeclampsia, Small-for-gestational-age, Soluble fms-like tyrosine kinase 1

\footnotetext{
* Correspondence: teresa.mary.macdonald@gmail.com

${ }^{1}$ Mercy Perinatal, Mercy Hospital for Women, Melbourne, VIC, Australia

${ }^{2}$ Department of Obstetrics and Gynaecology, University of Melbourne,

Melbourne, VIC, Australia

Full list of author information is available at the end of the article
}

(c) The Author(s). 2018 Open Access This article is distributed under the terms of the Creative Commons Attribution 4.0 International License (http://creativecommons.org/licenses/by/4.0/), which permits unrestricted use, distribution, and reproduction in any medium, provided you give appropriate credit to the original author(s) and the source, provide a link to the Creative Commons license, and indicate if changes were made. The Creative Commons Public Domain Dedication waiver (http://creativecommons.org/publicdomain/zero/1.0/) applies to the data made available in this article, unless otherwise stated. 


\section{Background}

Fetal growth restriction (FGR) due to placental insufficiency [1] is a major risk factor for stillbirth [2]. Sma ll-for-gestational-age (SGA, birthweight <10th centile) fetuses, a common surrogate classification for FGR, have three to four-fold increased stillbirth risk at every gestation [2-4]. A large prospective cohort study demonstrated that when SGA fetuses are detected and appropriately managed, the rate of stillbirth is halved compared to pregnancies where a SGA fetus remains undiagnosed [2].

Improved identification of FGR has been listed as a top 10 priority to reduce the global burden of stillbirth [5]. Measuring symphysis-fundal height is current practice for detecting the SGA fetus, despite low sensitivity, reported at $17-58 \%$ over the last decade [6-8]. While universal third trimester ultrasound improves detection of SGA fetuses beyond that of selective ultrasound, its sensitivity is only $57 \%$, with $35 \%$ positive predictive value [9]. A blood test able to detect the SGA fetus with better accuracy would provide clinicians with a valuable screening tool that may reduce the incidence of stillbirth.

Preeclampsia is associated with disordered release of angiogenesis-related factors into the maternal circulation reduced pro-angiogenic placental growth factor (PlGF) and increased anti-angiogenic soluble fms-like tyrosine kinase 1 (sFlt-1) [10-12]. A high sFlt-1:PlGF ratio is associated with preeclampsia, performs as a better predictor than either analyte alone $[13,14]$ and demonstrates high negative predictive value $[15,16]$.

Like preeclampsia, FGR is characterised by placental dysfunction which can lead to aberrant release of angiogenesis-related factors into the maternal circulation. The sFlt-1:PlGF ratio has been shown to be significantly higher in cases of ultrasound-diagnosed SGA fetuses [17], and in women where SGA fetuses have failed to be detected by routine third trimester ultrasound [18]. A nested case-control study specifically including pregnant women with ultrasound estimated fetal weight $>10$ th centile at 32-36 weeks' gestation, demonstrated significantly higher sFlt-1:PlGF ratios (at the same gestation as the ultrasound) among 80 cases of a term SGA infant compared to 80 controls, but with just $30 \%$ sensitivity at a $10 \%$ false positive rate (FPR) [18]. While a relationship between elevated sFlt-1:PIGF ratios and SGA fetuses has been described, the predictive value of the ratio at a single point in late pregnancy to identify the SGA, without ultrasound, has not been established.

Given that sFlt- 1 and PIGF are placenta-derived proteins, we hypothesised that measuring their levels at 36 weeks' gestation may be able to detect late-onset placental dysfunction to identify the SGA fetus, and to predict preeclampsia. We performed this nested case-control study from a large prospective cohort of 1000 pregnant women who had blood sampled at 36 weeks' gestation. We examined the performance of sFlt-1, PlGF and the sFlt-1:PlGF ratio at 36 weeks' gestation in the identification of women who subsequently gave birth to a SGA infant, or who developed preeclampsia.

\section{Methods}

This analysis is part of the Fetal Longitudinal Assessment of Growth (FLAG) study at the Mercy Hospital for Women, a tertiary maternity hospital in Melbourne with approximately 6000 births annually. The FLAG study (https://mercyperinatal.com/project/fetal-studies), designed to identify biomarkers to detect SGA fetuses, included prospective collection of 2015 blood samples from pregnant women at 36 weeks' gestation.

We performed a 1:2 nested case-control study using samples chosen from the first 1000 FLAG participants. We compared the 36 week sFlt-1, PlGF and sFlt-1:PlGF ratio values from women who delivered a SGA infant, to the analyte levels from a cohort of appropriate-for-gestational-age (AGA, birthweight $\geq 10$ th centile) controls, matched for maternal age, booking body mass index (BMI), smoking status, gestational diabetes mellitus (GDM), and parity. While a cohort study utilising all 1000 samples would be more powerful, and while case-control studies can be subject to overfitting, we used this nested case-control design to minimise costs. We made an a priori plan to proceed to a validation study utilising the remaining 1015 samples (from the subsequent FLAG study participants), which would mitigate the effects of any overfitting in the initial case-control study, if any analyte(s) demonstrated good diagnostic performance in predicting SGA infants.

This study was approved by the Mercy Health Research Ethics Committee (Ethics Approval Number R14/ 12) and written informed consent was obtained from all participants.

English-speaking women aged over 18 years, carrying a singleton pregnancy with normal mid-trimester morphology ultrasound were eligible to participate. Women booked to attend the Mercy Hospital for Women for their oral glucose tolerance test, offered around 28 weeks' gestation to diagnose GDM, were screened for eligibility and invited to participate between January 2015 and September 2016. Women who consented formed a convenience series of participants. Samples from women where a SGA fetus or preeclampsia were suspected at the time of blood sampling were not excluded. Whole blood was collected in a $10 \mathrm{ml}$ ethylenediaminetetraacetic acid tube at $35^{+0}$ to $37^{+0}$ weeks' gestation inclusive. Plasma was stored at $-80{ }^{\circ} \mathrm{C}$ until the time of PlGF and sFlt-1 measurement.

\section{Outcomes and diagnostic criteria}

Maternal characteristics and pregnancy outcomes were obtained from review of each participant's medical record, investigation results and hospital database entry, by 
a single clinician blinded to sFlt-1 and PIGF levels. Similarly, scientists performing the measurement of sFlt-1 and PIGF levels were blinded to the clinical characteristics and birthweight centiles of the participants. All sFlt-1 and PlGF levels were measured for research purposes only, and were not made available to any clinician involved in participants' obstetric care. Therefore there was no possibility of intervention bias.

Infant birthweights were assigned a customised centile using the GROW software [19] (http://www.gestation.net/), which generates a 'term optimal weight' based on an optimised fetal weight standard. We adjusted for the following non-pathological factors: maternal height, weight and parity; infant sex; and exact gestational age. Coefficients for the Australian dataset of GROW were informed by a local dataset; the multiple regression model has a constant to which weight is added or subtracted for each of the adjusted variables. SGA was defined as customised birthweight $<10$ th centile.

Preeclampsia was diagnosed according to The American College of Obstetricians and Gynecologists' Taskforce on Hypertension in Pregnancy definition [20]: new onset hypertension (blood pressure $\geq 140 \mathrm{mmHg}$ systolic, or $\geq$ $90 \mathrm{mmHg}$ diastolic on two occasions $\geq 4 \mathrm{~h}$ apart after 20 weeks' gestation); plus one of new-onset: proteinuria, thrombocytopaenia, renal insufficiency, impaired liver function, pulmonary oedema or cerebral symptoms.

We analysed the differences in sFlt-1, PIGF and sFlt-1:PlGF ratio values between the control group and three different case groups: (i) 'All SGA' - all cases where the infant was SGA, including cases of concurrent preeclampsia; (ii) 'SGA only' - cases of concurrent preeclampsia were excluded; (iii) 'Preeclampsia' - all cases of preeclampsia, regardless of birthweight centile.

For cases of birthweight <10th centile, we also searched hospital ultrasound records to see which cases (i) were referred for a clinically-indicated third trimester ultrasound scan which included biometry to estimate fetal weight, and (ii) which cases were identified by a third trimester ultrasound as SGA on the basis of EFW or abdominal circumference $<10$ th centile. This allowed us to compare the sensitivities of the analytes to detect SGA to that of current clinical practice - selective ultrasound - in our institution.

\section{Assessment of plasma analyte levels}

Maternal plasma levels of sFlt-1 and PlGF were measured with a commercial electrochemiluminescence immunoassay platform (Roche Diagnostics). Analysis of change in sFlt-1 and PlGF values over gestational age in days was made using LOWESS smooth and regression techniques of both mean and median values (Additional file 1: S2). There was no significant trend for either sFlt-1 or PlGF values seen across the gestational weeks where sampling was performed $\left(35^{+0}-37^{+0}\right.$ weeks), hence adjustment for gestational age was not performed.

\section{Statistical analysis}

Maternal characteristics and birth outcome data were compared for all women who delivered SGA infants, and for all cases of preeclampsia, against controls using unpaired t-test or rank-sum test for continuous data, according to distribution; and Chi-squared test for categorical data. Statistical analyses were performed using GraphPad Prism version 6 (GraphPad Software Inc., San Diego, CA) and Stata v14 (College Station, TX: StataCorp LP). Two-sided significance level was set at 0.05 .

We determined the sensitivities, at a predetermined $10 \%$ FPR, of sFlt-1, PlGF, and the sFlt:PlGF ratio for the detection of: (i) SGA <10th centile, with and without concurrent preeclampsia, (ii) SGA $<3$ rd centile, with and without concurrent preeclampsia, and (iii) Preeclampsia. Overall discrimination of the analytes for each disease group was assessed with area under the Receiver Operating Characteristic (ROC) curve analysis. In this nested case-control study positive predictive value (PPV) and negative predictive value (NPV) were calculated using the sampling fraction adjustment based upon the number of controls in this study compared to the original cohort and associated 95\% confidence limits were calculated using a logit based standard error [21].

We chose 10\% FPR as the cut-off as this is the FPR of universal ultrasound biometry at 36 weeks' gestation, as determined by the large, prospective, blinded Pregnancy Outcome Prediction study [9]. We chose to assess for SGA <10th centile, as this is considered by many to be an important threshold clinically [22]. In addition, customised birthweight $<10$ th centile was the threshold used to define FGR in the large population study of over 92,000 births that demonstrated a halving of stillbirth risk when fetuses below this threshold were detected antenatally [2]. We also evaluated the performance of the analytes to predict infants destined to be born at $<3$ rd centile as this was a cut-off agreed upon by recent Delphi procedure as a consensus definition of FGR [23].

\section{Results}

\section{Baseline characteristics}

Between March 2015 and February 2016 the first 1000 36 week FLAG study plasma samples were obtained. 105 (10.5\%) participants delivered a SGA infant, including seven with co-existent preeclampsia. There were $28(2.8 \%)$ cases of infant birthweight $<3$ rd centile (one with concurrent preeclampsia). There were 32 cases of preeclampsia among women with AGA newborns (39 (3.9\%) total preeclampsia cases). We matched the 105 women with SGA infants to 210 controls. Due to instrument error sFlt-1 values were not available for two SGA cases, and three controls (Fig. 1). 


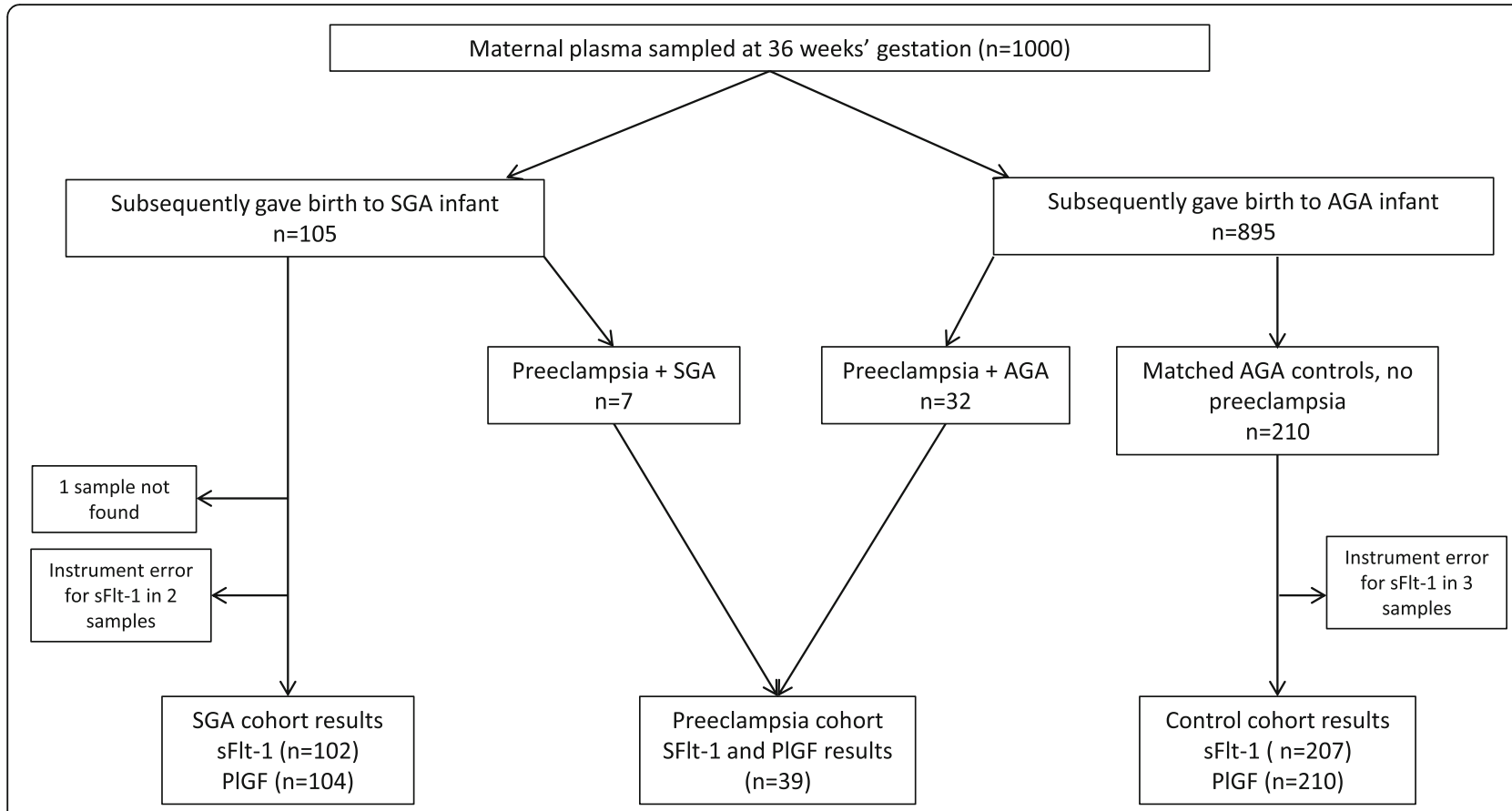

Fig. 1 Study profile. AGA = appropriate-for-gestational-age (customised birthweight $\geq 10$ th centile), $n=$ number, PIGF=Placental growth Factor, sFlt-1 = soluble fms-like tyrosine kinase 1, SGA = small-for-gestational-age (customised birthweight $<10$ th centile)

Maternal characteristics and birth outcomes for participants with complete sample analysis results are summarised in Table 1. There were no significant differences between controls and SGA cases except for birthweight, birthweight centiles and gestation at delivery: SGA infants were a mean $864 \mathrm{~g}$ and 46.8 centiles smaller, and were born 5 days' gestation earlier than control infants. Participants who developed preeclampsia had significantly higher booking BMI than controls (mean 27.4 vs $25.4 \mathrm{~kg} / \mathrm{m}^{2}$ ); and significantly higher emergency caesarean section rate. Infants of preeclamptic mothers were also significantly smaller than those of controls, and were born 5 days' gestation earlier.

Angiogenesis factor levels in cases compared to controls Analysis was performed according to three case groups: (i) 'All SGA' - concurrent preeclampsia cases included; (ii) 'SGA only' - concurrent preeclampsia cases excluded; (iii) 'Preeclampsia' - all preeclampsia cases included, regardless of birthweight centile. Each case group was independently compared to controls (AGA infant, no preeclampsia).

\section{(i) 'All SGA' vs controls}

The angiogenesis factors were all significantly altered in cases of SGA infants compared to controls (Fig. 2a, c, e, Table 2). When comparing 'All SGA' to controls, the median sFlt-1 level was significantly higher and the median PIGF level was significantly lower. Correspondingly, the median sFlt-1:PlGF ratio of the 'All SGA' cohort was significantly higher than that of controls (14.24 vs 7.11 respectively, $P<0.0001$ ).

\section{(ii) 'SGA only' vs controls}

When the angiogenesis factor levels were compared between controls and cases of 'SGA only' (excluding cases of co-existent preeclampsia) the differences between the groups became less pronounced (Fig. 2, Table 2). The median PlGF level remained significantly lower in 'SGA only' cases compared to controls, but there was no significant difference in sFlt-1 levels. The median sFlt-1:PIGF ratio of the 'SGA only' cases remained significantly higher than that of the controls (13.00 vs 7.11 respectively, $p=0.0006$ ).

\section{(iii) Preeclampsia versus controls}

The levels of the angiogenesis factors were all significantly different in cases of preeclampsia compared to controls (Fig. 3, Table 2). When comparing preeclampsia cases to controls, the median sFlt-1 level was significantly higher, and median PIGF was significantly lower. The median sFlt-1:PlGF ratio of the preeclampsia cohort was correspondingly significantly higher than that of the control group (54.25 vs 7.11 respectively, $P<0.0001$ ). 
Table 1 Participant characteristics compared between controls and: (i) those with a SGA infant; (ii) women who developed preeclampsia

\begin{tabular}{|c|c|c|c|c|c|}
\hline & Controls $(n=207)$ & All SGA $(n=102)$ & $P$ & Preeclampsia $(n=39)$ & $P$ \\
\hline Age (years) & $32.1(4.7)$ & $31.9(4.2)$ & 0.72 & $33.1(4.7)$ & 0.27 \\
\hline Booking Body Mass Index $\left(\mathrm{kg} / \mathrm{m}^{2}\right)$ & $25.4(4.6)$ & $25.4(5.8)$ & 0.45 & $27.6(6.0)$ & 0.02 \\
\hline \multicolumn{6}{|l|}{ Smoking status } \\
\hline Current smoker & $17(8.2 \%)$ & $8(7.8 \%)$ & 0.98 & $2(5.1 \%)$ & 0.80 \\
\hline Ex-smoker & $51(24.6 \%)$ & $26(25.5 \%)$ & & $10(25.6 \%)$ & \\
\hline Never & 139 (67.1\%) & $68(66.7 \%)$ & & $27(69.2 \%)$ & \\
\hline Gestational diabetes mellitus & $38(18.4 \%)$ & $18(17.6 \%)$ & 1.00 & $9(23.1 \%)$ & 0.51 \\
\hline \multicolumn{6}{|l|}{ Parity } \\
\hline 0 & $118(57.0 \%)$ & $58(56.9 \%)$ & 0.97 & $28(71.8 \%)$ & 0.20 \\
\hline 1 & $65(31.4 \%)$ & $33(32.4 \%)$ & & $9(23.1 \%)$ & \\
\hline$>1$ & $24(11.6 \%)$ & $11(10.8 \%)$ & & $2(5.1 \%)$ & \\
\hline \multicolumn{6}{|l|}{ Onset of delivery } \\
\hline Induction of labour & $88(42.5 \%)$ & $47(46.1 \%)$ & 0.08 & $19(48.7 \%)$ & 0.25 \\
\hline Spontaneous labour & $96(46.4 \%)$ & $36(35.3 \%)$ & & $13(33.3 \%)$ & \\
\hline No labour & $23(11.1 \%)$ & $19(18.6 \%)$ & & $7(17.9 \%)$ & \\
\hline \multicolumn{6}{|l|}{ Mode of delivery } \\
\hline Normal vaginal delivery & $102(49.3 \%)$ & $45(44.1 \%)$ & 0.64 & $11(28.2 \%)$ & 0.01 \\
\hline Instrumental delivery & $42(20.3 \%)$ & $22(21.6 \%)$ & & $7(17.9 \%)$ & \\
\hline Emergency caesarean & $42(20.3 \%)$ & $20(19.6 \%)$ & & $17(43.6 \%)$ & \\
\hline Elective caesarean & $21(10.1 \%)$ & $15(14.7 \%)$ & & $4(10.3 \%)$ & \\
\hline Birthweight (g) & $3547(444)$ & $2683(333)$ & $<0.0001$ & $3308(640)$ & 0.005 \\
\hline Birthweight centile & $52.1(26.1)$ & $5.3(3.0)$ & $<0.0001$ & $42.8(30.4)$ & 0.049 \\
\hline Gestational age at delivery (weeks ${ }^{+ \text {days }}$ ) & $39^{+5}\left(1^{+1}\right)$ & $39^{+0}\left(1^{+4}\right)$ & $<0.0001$ & $39^{+0}\left(1^{+4}\right)$ & 0.03 \\
\hline
\end{tabular}

Data represented as mean (standard deviation), or number (\%). $g$ grams, $k g$ kilograms, $m$ metres, $n$ number, PIGF placental growth factor, sFlt- 1 soluble fms-like tyrosine kinase 1, SGA small-for-gestational-age (birthweight $<10$ th centile). Note: some percentages do not sum to $100 \%$ due to rounding to one decimal place

\section{Sensitivity of the analytes to detect the SGA and preeclampsia}

The sensitivities of the analytes at a fixed 10\% FPR (90\% specificity) to predict birth of a SGA infant, or preeclampsia, are presented in Table 3. In Fig. 4 we have also presented the area under the ROC curve as a measure of overall discrimination for the analyte that had the greatest sensitivity for each of 'All SGA','SGA only' and 'Preeclampsia'.

For 'All SGA' and 'SGA only', at both $<10$ th and $<3$ rd centile definitions, sFlt-1 had sensitivities below 23\%. PIGF was the most sensitive analyte to detect both 'All SGA' and 'SGA only', but with sensitivities less than 33\%. For 'All SGA' and 'SGA only' at both $<10$ th and $<3$ rd centile definitions, the sFlt-1:PlGF ratio demonstrated less than 29\% sensitivity (Table 3). For PIGF, the area under the ROC curve was only 0.66 for 'All SGA'; with a similarly modest result for 'SGA only' (Fig. 4a \& b). Given these very modest performances for the detection of SGA fetuses, we did not think it would be cost-effective or valuable to proceed with the validation step in our second 1015 samples, so we did not perform it.
Seventy four (70.4\%) of the 105 cases of a SGA infant were referred for a third trimester ultrasound to estimate fetal weight (41 were performed between $35^{+0}$ and $37^{+0}$ weeks - the same gestation range as our blood samples). 24 (32.4\%) of the 74 third trimester ultrasound scans detected a SGA fetus with an EFW or abdominal circumference measurement <10th centile. Therefore, the strategy of selective ultrasound, in practice in our institution, performed with a sensitivity for SGA of $22.9 \%$ (24 out of 105 cases identified) overall.

All three analytes demonstrated moderate sensitivity, at over $56 \%$ for a $10 \%$ FPR, for preeclampsia (Table 3). The sFlt-1:PlGF ratio had the highest sensitivity for preeclampsia, at $69.2 \%$ with a $10 \%$ FPR. The sFlt-1:PlGF ratio performed moderately well on ROC curve analysis, with an area under the curve of 0.86 (Fig, 4c).

\section{Discussion}

The central role of the placenta in preeclampsia and FGR suggests that these two clinical conditions may share common plasma biomarkers. We therefore investigated the 

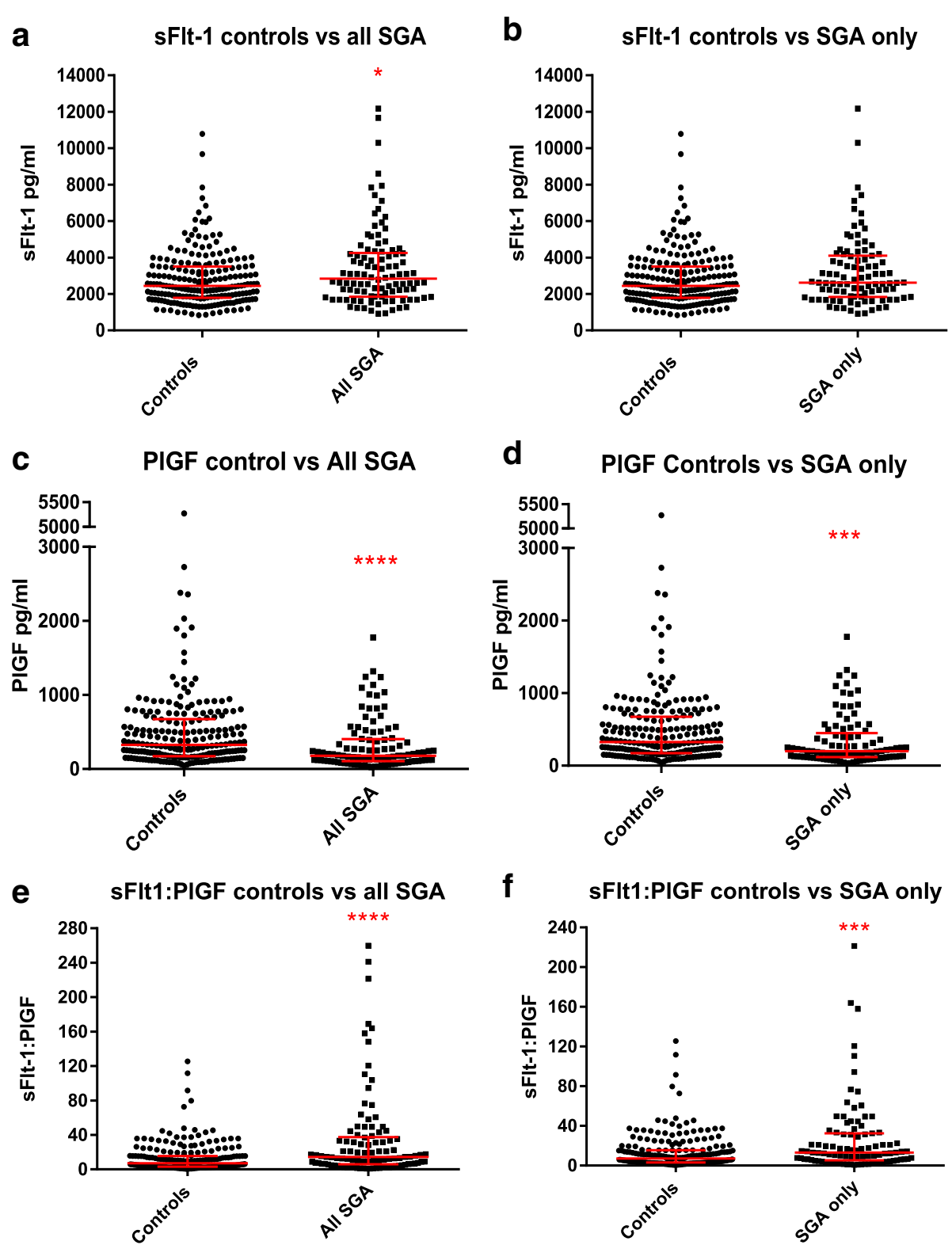

Fig. 2 Levels of angiogenesis-related factors in cases of small-for-gestational-age (SGA) fetuses compared to controls. a. soluble fms-like tyrosine kinase-1 (sFlt-1) levels in 'All SGA' cases and controls; b. sFlt-1 levels in 'SGA only' (excluding concurrent preeclampsia) cases and controls; $\mathbf{c}$. Placental growth factor (PIGF) levels in 'All SGA' cases and controls; d. PIGF levels in 'SGA only' cases and controls; e. sFlt-1:PIGF ratios in 'All SGA' cases and controls; $\mathbf{f}$. sFlt-1:PIGF ratios in 'SGA only' cases and controls. Medians and interquartile ranges shown. ${ }^{*}=P<0.05$, $* * *=P<0.001,{ }^{* * * *}=P<0.0001$

value of two known placenta-derived preeclampsia biomarkers (and their ratio), for the prediction of SGA infants in a large, independent, prospective cohort. Through analysis of samples obtained from a large unselected cohort, we found maternal plasma PlGF at 36 weeks' gestation to be significantly lower in women that subsequently gave birth to SGA infants compared to women with AGA newborns.

At a fixed 10\% FPR, low PlGF identified $32.1 \%$ of women who subsequently gave birth to a newborn with birthweight $<3$ rd centile, and $28.8 \%$ of those with a $<10$ th centile infant. Current tools for detection of late-onset FGR are poor. Significantly, a single PIGF level, even at the modest detection rates reported here, may still outperform the traditional methods of symphysis-fundal height [6], and selective ultrasound [9]. Indeed in our cohort, a strategy of selective ultrasound, the current clinical practice in our institution, predicted only $22.9 \%$ of SGA infants - comparatively less than PIGF would have. While the 
Table 2 sFlt-1, PIGF and sFlt-1:PIGF ratios compared between controls and: (i) cases with a SGA infant; (ii) preeclampsia cases

\begin{tabular}{lllllll}
\hline & Controls & All SGA & $P$ & SGA only & $P$ & Preeclampsia \\
\hline sFlt-1 (pg/ml) & 2446 & 2837 & 0.02 & 2620 & 0.10 & 4857 \\
& {$[1795-3503]$} & {$[1850-4250]$} & & {$[1835-4099]$} & & {$[3777-6941]$} \\
PIGF $(\mathrm{pg} / \mathrm{ml})$ & 326.7 & 178.5 & $<0.001$ & 199.9 & $<0.001$ & 99.73 \\
& {$[173.1-675.4]$} & {$[106.4-404.8]$} & & {$[118.1-448.6]$} & & {$[61.99-158.6]$} \\
sFlt-1:PIGF ratio & 7.11 & 14.24 & $<0.001$ & 13.00 & $<0.001$ & 54.25 \\
& {$[3.08-15.58]$} & {$[6.00-37.37]$} & & {$[5.27-32.44]$} & & {$[26.81-114.5]$} \\
\hline
\end{tabular}

Data presented as median [25th-75th percentile]. "All SGA" = Cases with a SGA fetuses including cases with co-existent preeclampsia; "SGA only" = Cases with SGA fetuses with cases of co-existant preeclampisa excluded; $\mathrm{pg} / \mathrm{ml}=$ picogram/millilitre, PIGF placental growth factor, sFlt-1 soluble fms-like tyrosine kinase-1, SGA small-for-gestational-age (birthweight $<10$ th centile). For sFlt-1 and sFlt-1:PIGF ratio results $n=207$ for controls, $n=102$ for 'All SGA', $n=39$ for 'Preeclampsia'. For PIGF results $n=210$ for controls, $n=104$ for 'All SGA', and $n=39$ for 'Preeclampsia'

predictive performance of PIGF alone is not sufficient to warrant adoption into clinical practice, our data supports the potential of a multi-biomarker approach. We also report that sFlt-1 is not significantly altered in pregnancies with a SGA fetus unless preeclampsia is present, suggesting sFlt-1 to be a biomarker more specific to preeclampsia.

Our study also validated the diagnostic performance of the sFlt-1:PlGF ratio at 36 weeks' gestation for late-onset preeclampsia. When we applied the same ratio cut-off $(\geq 38 \mathrm{pg} / \mathrm{ml}$ ) as used in the PROGNOSIS study [15] to our cohort, $66.7 \%$ sensitivity and $94.2 \%$ specificity were achieved
(Table 4), surpassing the performance reported in the original trial for preeclampsia within 4 weeks of testing [15]. Application of the $\geq 38 \mathrm{pg} / \mathrm{ml}$ cut-off did not perform as well to predict SGA infants however, displaying sensitivities of $24.5 \%$ and $25.0 \%$ for $<10$ th and $<3$ rd centile birthweight respectively (Table 4). Overall, the data from our study acts to validate some of the results from the PROGNOSIS study in an independent cohort, strengthening the potential clinical utility of the ratio for detecting late-onset preeclampsia.

The strength of this study was our large prospective cohort of 1000 singleton pregnancies from which
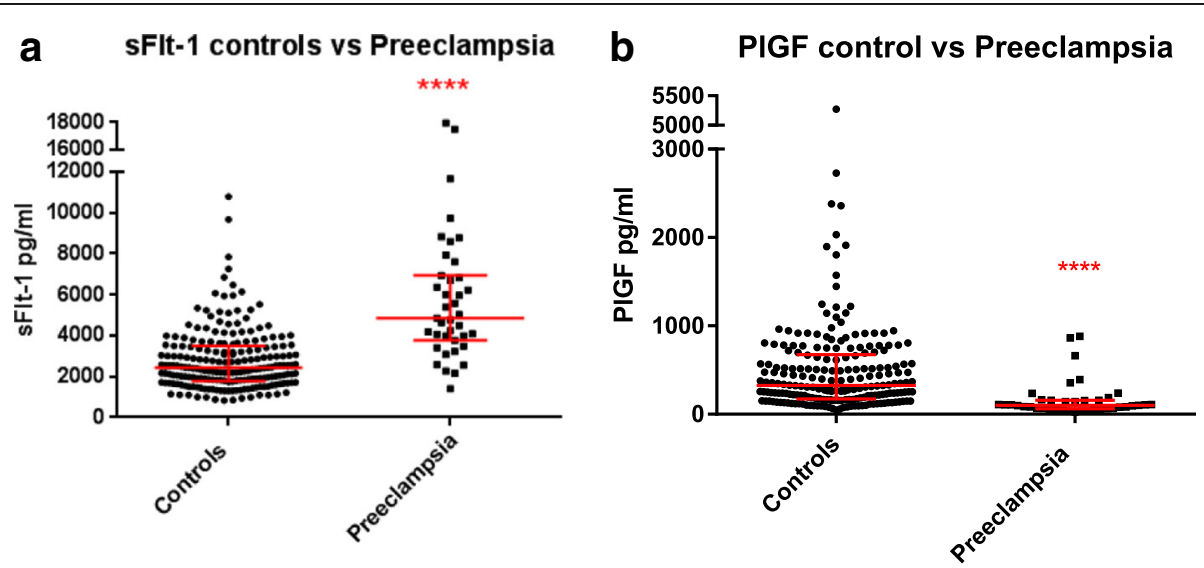

C sFIt1:PIGF controls vs Preeclampsia

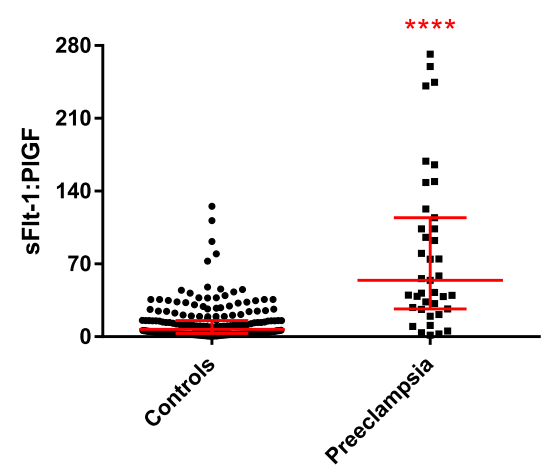

Fig. 3 Levels of angiogenesis-related factors in cases of preeclampsia compared to controls. a. soluble fms-like tyrosine kinase-1 (sFlt-1) levels in preeclampsia cases and controls; b. Placental growth factor (PIGF) levels in preeclampsia cases and controls; c. sFIt-1:PIGF ratios in preeclampsia cases and controls. Medians and interquartile ranges shown. ${ }^{* * *}=P<0.0001$ 
Table 3 Diagnostic performance of each analyte to predict $<10$ th and $<3$ rd centile infants, and preeclampsia

\begin{tabular}{|c|c|c|c|c|c|}
\hline Outcome & Analyte and cut-point & Sensitivity & Specificity & PPV & NPV \\
\hline \multirow[t]{3}{*}{ Birthweight < 10th centile (All SGA) } & sFlt-1 > $4570 \mathrm{pg} / \mathrm{ml}$ & $\begin{array}{l}19.6 \% \\
{[12.4-28.6 \%]}\end{array}$ & $\begin{array}{l}89.9 \% \\
{[84.9-93.6 \%]}\end{array}$ & $\begin{array}{l}18.0 \% \\
{[11.1-27.9 \%]}\end{array}$ & $\begin{array}{l}90.8 \% \\
{[89.8-91.6 \%]}\end{array}$ \\
\hline & $\mathrm{PIGF}<117.3 \mathrm{pg} / \mathrm{ml}$ & $\begin{array}{l}28.8 \% \\
{[20.4-38.6 \%]}\end{array}$ & $\begin{array}{l}89.5 \% \\
{[84.6-93.3 \%]}\end{array}$ & $\begin{array}{l}24.2 \% \\
{[16.3-34.5 \%]}\end{array}$ & $\begin{array}{l}91.6 \% \\
{[90.5-92.5 \%]}\end{array}$ \\
\hline & sFlt-1:PIGF > 33.4 & $\begin{array}{l}26.5 \% \\
{[18.2-36.1 \%]}\end{array}$ & $\begin{array}{l}89.9 \% \\
{[84.9-93.6 \%]}\end{array}$ & $\begin{array}{l}22.9 \% \\
{[15.0-33.2 \%]}\end{array}$ & $\begin{array}{l}91.5 \% \\
{[90.5-92.4 \%]}\end{array}$ \\
\hline \multirow[t]{3}{*}{ Birthweight < 10th centile (SGA only) } & sFlt-1 > $4570 \mathrm{pg} / \mathrm{ml}$ & $\begin{array}{l}16.8 \% \\
{[9.9-25.9 \%]}\end{array}$ & $\begin{array}{l}89.9 \% \\
{[84.9-93.6 \%]}\end{array}$ & $\begin{array}{l}14.8 \% \\
{[8.7-24.2 \%]}\end{array}$ & $\begin{array}{l}91.1 \% \\
\text { [90.3-91.9\%] }\end{array}$ \\
\hline & $\mathrm{PIGF}<117.3 \mathrm{pg} / \mathrm{ml}$ & $\begin{array}{l}24.7 \% \\
{[16.5-34.5 \%]}\end{array}$ & $\begin{array}{l}89.5 \% \\
{[84.6-93.3 \%]}\end{array}$ & $\begin{array}{l}20.2 \% \\
{[13.0-30.0 \%]}\end{array}$ & $\begin{array}{l}91.7 \% \\
{[90.7-92.6 \%]}\end{array}$ \\
\hline & sFlt-1:PIGF > 33.4 & $\begin{array}{l}22.1 \% \\
{[14.2-31.8 \%]}\end{array}$ & $\begin{array}{l}89.9 \% \\
{[84.9-93.6 \%]}\end{array}$ & $\begin{array}{l}18.6 \% \\
{[11.6-28.5 \%]}\end{array}$ & $\begin{array}{l}91.7 \% \\
{[90.7-92.5 \%]}\end{array}$ \\
\hline \multirow[t]{3}{*}{ Birthweight < 3rd centile (All SGA) } & $\mathrm{sFlt}-1>4570 \mathrm{pg} / \mathrm{ml}$ & $\begin{array}{l}21.4 \% \\
{[8.3-41.0 \%]}\end{array}$ & $\begin{array}{l}87.5 \% \\
{[83.1-91.2 \%]}\end{array}$ & $\begin{array}{l}4.7 \% \\
{[2.2-9.7 \%]}\end{array}$ & $\begin{array}{l}97.5 \% \\
{[96.9-97.9 \%]}\end{array}$ \\
\hline & $\mathrm{PIGF}<117.3 \mathrm{pg} / \mathrm{ml}$ & $\begin{array}{l}32.1 \% \\
{[15.9-52.4 \%]}\end{array}$ & $\begin{array}{l}85.0 \% \\
{[80.3-88.9 \%]}\end{array}$ & $\begin{array}{l}5.8 \% \\
{[3.3-10.1 \%]}\end{array}$ & $\begin{array}{l}97.8 \% \\
{[97.1-98.3 \%]}\end{array}$ \\
\hline & sFIt-1:PIGF > 33.4 & $\begin{array}{l}28.6 \% \\
{[13.2-48.7 \%]}\end{array}$ & $\begin{array}{l}85.8 \% \\
{[81.1-89.6 \%]}\end{array}$ & $\begin{array}{l}5.5 \% \\
{[2.9-10.0 \%]}\end{array}$ & $\begin{array}{l}97.7 \% \\
{[97.0-98.1 \%]}\end{array}$ \\
\hline \multirow[t]{3}{*}{ Birthweight < 3rd centile (SGA only) } & sFlt-1 $>4570 \mathrm{pg} / \mathrm{ml}$ & $\begin{array}{l}22.2 \% \\
{[8.6-42.3 \%]}\end{array}$ & $\begin{array}{l}88.7 \% \\
{[84.4-92.2 \%]}\end{array}$ & $\begin{array}{l}5.2 \% \\
{[2.4-10.7 \%]}\end{array}$ & $\begin{array}{l}97.6 \% \\
{[97.1-98.1 \%]}\end{array}$ \\
\hline & $\mathrm{PIGF}<117.3 \mathrm{pg} / \mathrm{ml}$ & $\begin{array}{l}29.6 \% \\
{[13.8-50.2 \%]}\end{array}$ & $\begin{array}{l}86.4 \% \\
{[81.9-90.2 \%]}\end{array}$ & $\begin{array}{l}5.7 \% \\
{[3.1-10.4 \%]}\end{array}$ & $\begin{array}{l}97.8 \% \\
\text { [97.2-98.3\%] }\end{array}$ \\
\hline & sFlt-1:PIGF > 33.4 & $\begin{array}{l}25.9 \% \\
{[11.1-46.3 \%]}\end{array}$ & $\begin{array}{l}87.3 \% \\
{[82.7-91.0 \%]}\end{array}$ & $\begin{array}{l}5.4 \% \\
{[2.7-10.3 \%]}\end{array}$ & $\begin{array}{l}97.7 \% \\
{[97.1-98.2 \%]}\end{array}$ \\
\hline \multirow[t]{3}{*}{ Preeclampsia } & sFlt-1 $>4570 \mathrm{pg} / \mathrm{ml}$ & $\begin{array}{l}56.4 \% \\
{[39.6-72.2 \%]}\end{array}$ & $\begin{array}{l}89.9 \% \\
{[84.9-93.6 \%]}\end{array}$ & $\begin{array}{l}18.4 \% \\
{[12.1-26.9 \%]}\end{array}$ & $\begin{array}{l}98.1 \% \\
{[97.3-98.6 \%]}\end{array}$ \\
\hline & $\mathrm{PIGF}<117.3 \mathrm{pg} / \mathrm{ml}$ & $\begin{array}{l}64.1 \% \\
{[47.2-78.8 \%]}\end{array}$ & $\begin{array}{l}89.5 \% \\
{[84.6-93.3 \%]}\end{array}$ & $\begin{array}{l}19.9 \% \\
{[13.6-28.2 \%]}\end{array}$ & $\begin{array}{l}98.4 \% \\
\text { [97.6-98.9\%] }\end{array}$ \\
\hline & sFIt-1:PIGF > 33.4 & $\begin{array}{l}69.2 \% \\
{[52.4-83.0 \%]}\end{array}$ & $\begin{array}{l}89.9 \% \\
{[84.9-93.6 \%]}\end{array}$ & $\begin{array}{l}21.7 \% \\
{[14.9-30.4 \%]}\end{array}$ & $\begin{array}{l}98.6 \% \\
{[97.8-99.1 \%]}\end{array}$ \\
\hline
\end{tabular}

Data presented with [95\% Confidence Interval]. *determined by a false positive rate of $10 \%$ in the birthweight $\geq 10$ th centile and no preeclampsia control group. "All SGA" = Cases of SGA fetuses including cases with co-existent preeclampsia; "SGA only" = Cases of SGA fetuses with cases of co-existant preeclampisa excluded; NPV Negative Predictive value, pg/ml = pictogram/millilitre, PIGF placental growth factor, PPV Positive Predictive Value, sFlt-1 soluble fms-like tyrosine kinase-1, SGA small-for-gestational-age

case-control samples were selected. Previous studies have investigated the relationships between sFlt-1 and/or PIGF and late-onset FGR, but most have utilized methods not readily translated into clinical practice for a general antenatal population. These methods include placental rather than plasma protein analysis [24]; multi-modality integrated models $[25,26]$; prior ultrasound diagnosis of SGA [27-33]; and investigation confined to cases of preterm infants [32]. Our large cohort specifically enabled us to compare the utility of sFlt-1, PlGF, and their ratio, in all cases of a SGA infant as well as in a 'SGA only' cohort, actively removing the impact of participants with concurrent preeclampsia. Our results add clarity where previous findings have been inconsistent. Prior to this study, elevated sFlt-1 had been associated with FGR in some animal [34], and human [31, 32, 35, 36] studies with cases of preeclampsia excluded, but not in others $[18,33]$. The large numbers in our study and the ability to test levels in both 'All SGA' and 'SGA only' cohorts have allowed us to confidently define sFlt-1 as a biomarker more specific to preeclampsia, rather than FGR.

Previous studies have measured the analytes at a variety of gestations, including first $[26,37]$ and second trimesters [38], in a longitudinal fashion [12], and at delivery [31, 39]. However, early measurement of the angiogenic factors is not predictive of late-onset disease [38], except if included in a complex model incorporating several maternal, ultrasonographic and blood-based risk factor assessments [26] difficult to incorporate into clinical practice. In preeclampsia, the predictive performance of the analytes is improved when measured closer to the onset of disease [15]. Future biomarkers requiring only single blood sampling at 36 weeks' gestation would have the potential to be rapidly incorporated into clinical practice, with the availability of safe, acceptable interventions (surveillance and planned timely delivery) to reduce stillbirth risk for SGA fetuses.

While the predictive potential of a single measurement of the sFlt-1:PlGF ratio at 36 weeks' gestation has been 

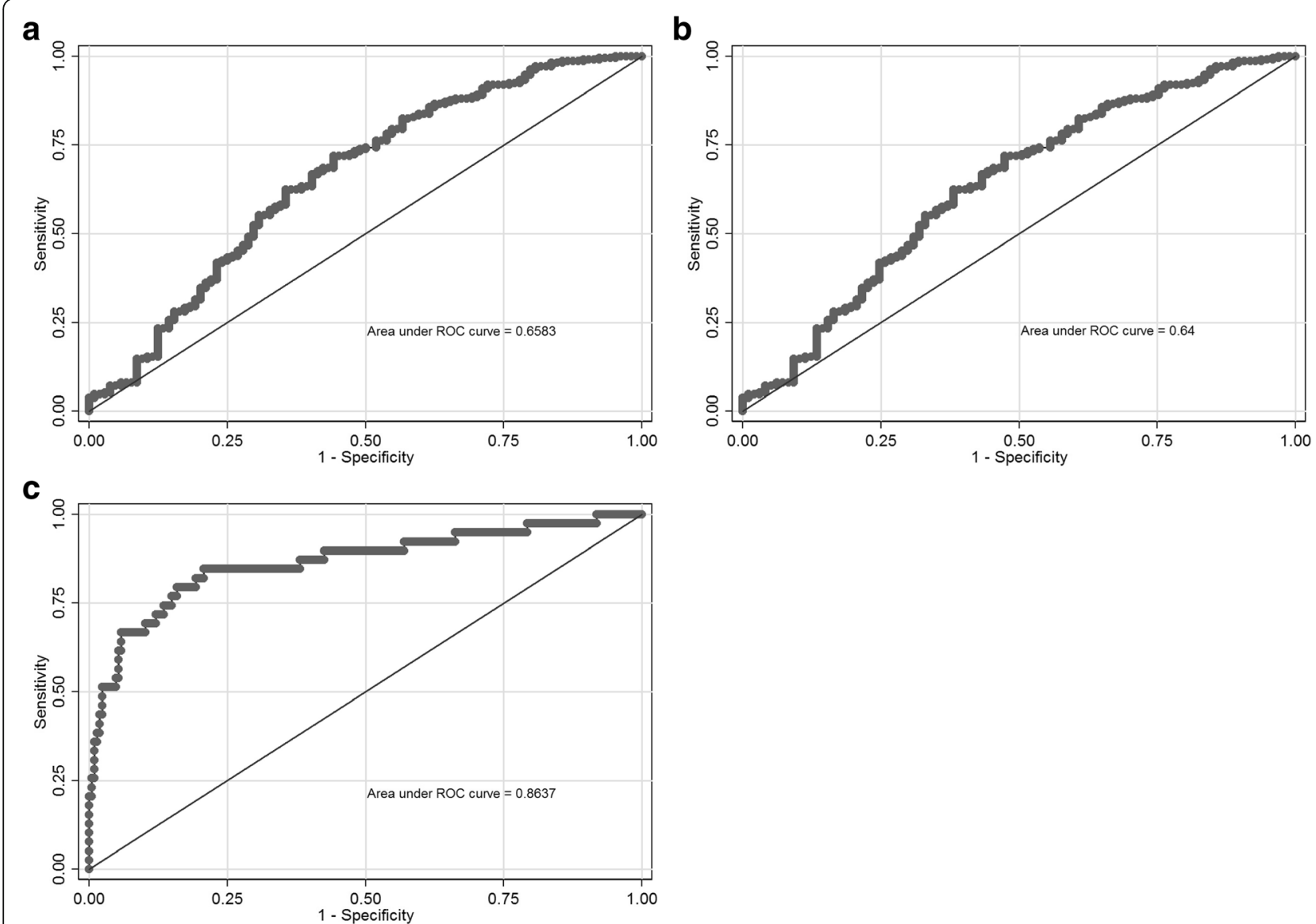

Fig. 4 Receiver operating characteristic curves for most sensitive analytes to detect small-for-gestational-age (SGA) infants, or preeclampsia. a. ROC curve for the performance of placental growth factor (PIGF) in detecting 'All SGA' - including cases of concurrent preeclampsia; b. ROC curve for the performance of PIGF in detecting 'SGA only' - excluding cases of concurrent preeclampsia; c. ROC curve for the performance of the soluble fms-like tyrosine kinase 1:PIGF ratio in detecting preeclampsia

assessed for preeclampsia [16], only the Pregnancy Outcome Prediction (POP) study has previously analysed the sFlt-1:PlGF ratio specifically at 36 weeks' gestation for FGR [40]. This study defined FGR as birthweight $<10$ th centile plus perinatal morbidity and/or preeclampsia and found the combination of sFlt-1:PlGF ratio $>38$ and ultrasound EFW <10th centile - both present together in just $3 \%$ of participants - to demonstrate a higher PPV (21.6\%) and specificity (98\%) than either parameter alone, but with lower sensitivity (only $38 \%$ ) compared to either test alone. In this study, a 36 week PlGF value among the lowest decile performed with almost exactly the same diagnostic accuracy as the highest decile of the sFlt-1:PIGF ratio to identify FGR. Both tests performed with $43.1 \%$ sensitivity, $90.6 \%$ specificity, $6.7 \%$ PPV and 99\% NPV for the definition of FGR in use [40].

Table 4 Diagnostic performance of sFIt-1:PIGF ratio $\geq 38$ for preeclampsia, and $<10$ th and $<3$ rd centile infants

\begin{tabular}{lllll}
\hline Outcome & Sensitivity & Specificity & PPV & NPV \\
\hline Preeclampsia & $66.7 \%$ & $94.2 \%$ & $31.8 \%$ & $98.6 \%$ \\
Birthweight < 10th centile (All SGA) & {$[49.8-80.9 \%]$} & {$[90.1-97.0 \%]$} & {$[20.5-45.8 \%]$} & {$[97.8-99.1 \%]$} \\
& $24.5 \%$ & $94.2 \%$ & $32.4 \%$ & $91.7 \%$ \\
Birthweight <3rd centile (All SGA) & {$[16.5-34.0 \%]$} & {$[90.1-97.0 \%]$} & {$[20.1-47.8 \%]$} & {$[90.7-92.5 \%]$} \\
& $25.0 \%$ & $89.3 \%$ & $6.3 \%$ & $97.6 \%$ \\
\hline
\end{tabular}

Data presented with [95\% Confidence Interval]. NPV Negative Predictive value, PIGF placental growth factor, PPV Positive Predictive Value, sFlt-1 soluble fms-like tyrosine kinase-1, SGA small-for-gestational-age 
This mirrors the finding in our study, that the addition of sFlt-1 to PlGF in the form of the ratio at 36 weeks' gestation adds no value. It is also not surprising that the sensitivities reported for the analytes alone were higher in the POP study compared to ours - as the POP definition of FGR occurred in only $1.5 \%$ of the population. Interestingly, in the POP cohort, sFlt-1:PlGF ratio $>38$ demonstrated $37.2 \%$ sensitivity for birth weight $<3$ rd centile. This was much higher than the $25 \%$ sensitivity seen in our study. However, the POP study utilised a large cohort study in comparison to our nested case-control design; and used a population reference to define birthweight centile in contrast to customised birth weight centiles.

One other previous study measured sFlt-1 and PlGF at 35-37 weeks' gestation and reported their ability, in combination with ultrasound biometry and maternal characteristics, to predict SGA infants in the absence of preeclampsia, but did not assess the sFlt-1:PlGF ratio [36]. Again, similar to our findings, while addition of PlGF to biometry and maternal characteristics marginally improved the detection of SGA fetuses, addition of sFlt-1 did not [36]. Measurement of the analytes at a single time-point in late pregnancy was a strength of our study, adding to this body of evidence, as was our direct comparison of the sFlt-1:PlGF ratio to its constituent analytes.

The generalisability of our data is supported by the incidence of both preeclampsia and SGA infants among our participants, in keeping with expected rates [9, 41-43]. We present a well-characterised cohort, featuring a control group carefully matched for factors known to influence fetal growth. We used GROW software [19] to customise birthweight centiles, as this customised standard has stronger associations with adverse perinatal outcomes attributable to placental insufficiency than population references [44]. Additionally, the Elecsys immunoassays used for sFlt-1 and PIGF (Roche Diagnostics) have received Conformité Européene marking for use as in vitro medical devices.

One potential reason that PIGF displayed relatively low detection of SGA infants is that 'SGA' is not a functional diagnosis, and therefore may include infants who are constitutionally, rather than pathologically, small. Constitutionally small fetuses would not be expected to exhibit a low PlGF, as they are not suffering placental insufficiency. This in part may explain why PIGF levels, although significantly different, were not able to differentiate between cases and controls with both high sensitivity and specificity. However, PIGF was also not able to predict $<3$ rd centile infants, those largely regarded to be growth restricted [23], with great accuracy which suggests that while low PlGF is associated with placental insufficiency, the strength of association is not strong enough for its use as a biomarker in isolation.

Overall, our study demonstrates that PlGF may be a useful component of a multi-biomarker predictive blood test for
SGA, which we aim to develop. Our sFlt-1 results highlight that FGR and preeclampsia do not share the same plasma biomarker profile, such that future studies dedicated to FGR-specific biomarkers are needed. However, there are many challenges to performing well-conducted prospective studies, including the large numbers of participants required, and substantial associated costs. Despite this, we believe that future biomarkers requiring only single blood sampling at 36 weeks' gestation would have the potential to be rapidly incorporated into clinical practice, with the availability of safe, acceptable interventions (surveillance and planned timely delivery) to reduce stillbirth risk for SGA fetuses.

\section{Conclusions}

Thirty-six week plasma PIGF is significantly lower in women who subsequently deliver a SGA infant, but its diagnostic performance limits clinical translation as an individual biomarker. Further research is required to identify other biomarkers for FGR that together may perform with high sensitivity and specificity. The sFlt-1:PlGF ratio at 36 weeks however predicts preeclampsia with $69.2 \%$ sensitivity for $90 \%$ specificity, and therefore may be useful in triaging antenatal surveillance.

\section{Additional files}

Additional file 1: S1. Assessment for variation in analytes due to gestation. (DOCX $12070 \mathrm{~kb}$ )

Additional file 2: S2. Study data. (XLSX $104 \mathrm{~kb}$ )

\section{Abbreviations}

AGA: Appropriate-for-gestational-age (birthweight $\geq 10$ th centile); BMI: Body Mass Index; FGR: Fetal growth restriction; FLAG: Fetal Longitudinal Assessment of Growth; FPR: False positive rate; g: Grams; GDM: Gestational Diabetes Mellitus; kg: Kilograms; m: Metres; n: Number; NPV : Negative Predictive Value; PIGF : Placental growth factor; PPV : Positive Predictive Value; ROC: Receiver Operating Characteristic; sFlt-1: Soluble fms-like tyrosine kinase 1; SGA : Small-for-gestational-age (birthweight <10th centile)

\section{Acknowledgments}

We wish to thank the pathology, health information services, and antenatal clinic staff at the Mercy Hospital for Women for their assistance in conducting this research.

\section{Funding}

National Health and Medical Research Council Grant \#1065854, and Stillbirth Foundation Grant to SW; Australian Government Research Training Program Scholarship, and RANZCOG Taylor Hammond Scholarship to TM; National Health and Medical Research Council Early Career Fellowship \#1105603 to LH; Norman Beischer Medical Research Foundation to TK, TM and SW. Funding sources had no involvement in study design, collection or analysis of data, or in the writing or submission of this manuscript.

Availability of data and materials

Data generated and analysed during this study are included in this published article and its supplementary information files (Additional file 2: S1).

Authors' contributions

ST conceived the study. ST, SPW, TMM, LH, KMD, SPB and TJK designed the study. TMM, KMD and ALM recruited participants and performed sample 
collection. TMM characterised the cohort, and matched the control cohort. CT, TJK, PC and SPB performed sample preparation and analyte measurement processes. RJH, TMM and TJK performed data analysis. TMM wrote the first draft of the paper and all authors provided input and approved the final manuscript.

\section{Ethics approval and consent to participate}

This study was approved by the Mercy Health Research Ethics Committee (Ethics Approval Number R14/12) and written informed consent was obtained from all participants.

\section{Consent for publication}

Not applicable.

\section{Competing interests}

The authors declare that they have no competing interests.

\section{Publisher's Note}

Springer Nature remains neutral with regard to jurisdictional claims in published maps and institutional affiliations.

\section{Author details}

'Mercy Perinatal, Mercy Hospital for Women, Melbourne, VIC, Australia. ${ }^{2}$ Department of Obstetrics and Gynaecology, University of Melbourne, Melbourne, VIC, Australia. ${ }^{3}$ Translational Obstetrics Group, University of Melbourne, Melbourne, VIC, Australia. ${ }^{4}$ Department of Laboratory Services, Royal Children's Hospital, Melbourne, VIC, Australia. ${ }^{5}$ Department of Maternal-Fetal Medicine, Royal Women's Hospital, Melbourne, VIC, Australia.

\section{Received: 22 January 2018 Accepted: 23 August 2018}

\section{Published online: 31 August 2018}

\section{References}

1. Flenady V, Koopmans L, Middleton P, Froen JF, Smith GC, Gibbons K, Coory M, Gordon A, Ellwood D, McIntyre HD, et al. Major risk factors for stillbirth in high-income countries: a systematic review and meta-analysis. Lancet. 2011; 377:1331-40.

2. Gardosi J, Madurasinghe V, Williams M, Malik A, Francis A. Maternal and fetal risk factors for stillbirth: population based study. BMJ. 2013;346:f108.

3. Vashevnik S, Walker S, Permezel M. Stillbirths and neonatal deaths in appropriate, small and large birthweight for gestational age fetuses. Aust N Z J Obstet Gynaecol. 2007;47:302-6.

4. Mendez-Figueroa H, Truong VT, Pedroza C, Khan AM, Chauhan SP. Small-forgestational-age infants among uncomplicated pregnancies at term: a secondary analysis of 9 maternal-fetal medicine units network studies. Am J Obstet Gynecol. 2016;215:628.e621-7.

5. Pattinson R, Kerber K, Buchmann E, Friberg IK, Belizan M, Lansky S, Weissman E, Mathai M, Rudan I, Walker N, Lawn JE. Stillbirths: how can health systems deliver for mothers and babies? Lancet. 2011;377:1610-23.

6. Sparks TN, Cheng YW, McLaughlin B, Esakoff TF, Caughey AB. Fundal height: a useful screening tool for fetal growth? J Matern Fetal Neonatal Med. 2011;24:708-12.

7. Hargreaves K, Cameron M, Edwards H, Gray R, Deane K. Is the use of symphysis-fundal height measurement and ultrasound examination effective in detecting small or large fetuses? J Obstet Gynaecol. 2011;31:380-3.

8. Goto E. Prediction of low birthweight and small for gestational age from symphysis-fundal height mainly in developing countries: a meta-analysis. J Epidemiol Community Health. 2013:67:999-1005.

9. Sovio U, White IR, Dacey A, Pasupathy D, Smith GC. Screening for fetal growth restriction with universal third trimester ultrasonography in nulliparous women in the pregnancy outcome prediction (POP) study: a prospective cohort study. Lancet. 2015;386:2089-97.

10. Kwiatkowski S, Dolegowska B, Kwiatkowska E, Rzepka R, Marczuk N, Loj B, Torbe A. Maternal endothelial damage as a disorder shared by early preeclampsia, late preeclampsia and intrauterine growth restriction. J Perinat Med. 2016

11. Crispi F, Dominguez C, Llurba E, Martin-Gallan P, Cabero L, Gratacos E. Placental angiogenic growth factors and uterine artery Doppler findings for characterization of different subsets in preeclampsia and in isolated intrauterine growth restriction. Am J Obstet Gynecol. 2006;195:201-7.
12. Romero R, Nien JK, Espinoza J, Todem D, Fu W, Chung H, Kusanovic JP, Gotsch F, Erez O, Mazaki-Tovi S, et al. A longitudinal study of angiogenic (placental growth factor) and anti-angiogenic (soluble endoglin and soluble vascular endothelial growth factor receptor-1) factors in normal pregnancy and patients destined to develop preeclampsia and deliver a small for gestational age neonate. J Matern Fetal Neonatal Med. 2008;21:9-23.

13. Villa PM, Hamalainen E, Maki A, Raikkonen K, Pesonen AK, Taipale P, Kajantie E, Laivuori H. Vasoactive agents for the prediction of early- and late-onset preeclampsia in a high-risk cohort. BMC Pregnancy Childbirth. 2013;13:110.

14. Verlohren S, Herraiz I, Lapaire O, Schlembach D, Moertl M, Zeisler H, Calda P, Holzgreve W, Galindo A, Engels T, et al. The sFIt-1/PIGF ratio in different types of hypertensive pregnancy disorders and its prognostic potential in preeclamptic patients. Am J Obstet Gynecol. 2012;206(58):e51-8.

15. Zeisler H, Llurba E, Chantraine F, Vatish M, Staff AC, Sennstrom M, Olovsson M, Brennecke SP, Stepan H, Allegranza D, et al. Predictive value of the sFlt-1:PIGF ratio in women with suspected preeclampsia. N Engl J Med. 2016;374:13-22.

16. Sovio U, Gaccioli F, Cook E, Hund M, Charnock-Jones DS, Smith GC. Prediction of preeclampsia using the soluble fms-like tyrosine kinase 1 to placental growth factor ratio: a prospective cohort study of unselected nulliparous women. Hypertension. 2017;69:731-8.

17. Schoofs K, Grittner U, Engels T, Pape J, Denk B, Henrich W, Verlohren S. The importance of repeated measurements of the sFlt-1/PIGF ratio for the prediction of preeclampsia and intrauterine growth restriction. J Perinat Med. 2014;42:61-8.

18. Triunfo S, Parra-Saavedra M, Rodriguez-Sureda V, Crovetto F, Dominguez C, Gratacos E, Figueras F. Angiogenic factors and Doppler evaluation in normally growing fetuses at routine third-trimester scan: prediction of subsequent low birth weight. Fetal Diagn Ther. 2016;40:13-20.

19. Customised Weight Centile Calculator-GROW-Centile v.5.12/6.2. http:// www.gestation.net/.

20. The American College of Obstetricians and Gynecaologists. Task force on hypertension in pregnancy. Hypertension in pregnancy. Pp. 100. Acog.Org; 2013. p. 100

21. van Zaane $B$, Vergouwe $Y$, Donders AR, Moons KG. Comparison of approaches to estimate confidence intervals of post-test probabilities of diagnostic test results in a nested case-control study. BMC Med Res Methodol. 2012;12:166

22. The Royal College of Obstetricians and Gynaecologists. The investigation and management of the small-for-gestational-age fetus. In: RCOG Green-top Guideline No 31, 2nd edition; 2013.

23. Gordijn SJ, Beune IM, Thilaganathan B, Papageorghiou A, Baschat AA, Baker PN, Silver RM, Wynia K, Ganzevoort W. Consensus definition of fetal growth restriction: a Delphi procedure. Ultrasound Obstet Gynecol. 2016;48:333-9.

24. Rajakumar A, Jeyabalan A, Markovic N, Ness R, Gilmour C, Conrad KP. Placental HIF-1 alpha, HIF-2 alpha, membrane and soluble VEGF receptor-1 proteins are not increased in normotensive pregnancies complicated by late-onset intrauterine growth restriction. Am J Physiol Regul Integr Comp Physiol. 2007;293:R766-74.

25. Miranda J, Rodriguez-Lopez M, Triunfo S, Sairanen M, Kouru H, Parra-Saavedra M, Crovetto F, Figueras F, Crispi F, Gratacos E. Prediction of fetal growth restriction using estimated fetal weight versus a combined screening model at 32-36 weeks of gestation. Ultrasound Obstet Gynecol. 2016;

26. Crovetto F, Triunfo S, Crispi F, Rodriguez-Sureda V, Roma E, Dominguez C, Gratacos E, Figueras F. First-trimester screening with specific algorithms for earlyand late-onset fetal growth restriction. Ultrasound Obstet Gynecol. 2016;48:340-8.

27. Triunfo S, Lobmaier S, Parra-Saavedra M, Crovetto F, Peguero A, Nadal A, Gratacos E, Figueras F. Angiogenic factors at diagnosis of late-onset small-for-gestational age and histological placental underperfusion. Placenta. 2014;35:398-403.

28. Margossian A, Boisson-Gaudin C, Subtil F, Rudigoz RC, Dubernard G, Allias F, Huissoud C. Intra-uterine growth restriction impact on maternal serum concentration of PIGF (placental growth factor): a case control study. Gynecol Obstet Fertil. 2016;44:23-8.

29. Herraiz I, Droge LA, Gomez-Montes E, Henrich W, Galindo A, Verlohren S. Characterization of the soluble fms-like tyrosine kinase-1 to placental growth factor ratio in pregnancies complicated by fetal growth restriction. Obstet Gynecol. 2014;124:265-73.

30. Benton SJ, McCowan LM, Heazell AE, Grynspan D, Hutcheon JA, Senger C, Burke O, Chan Y, Harding JE, Yockell-Lelievre J, et al. Placental growth factor as a marker of fetal growth restriction caused by placental dysfunction. Placenta. 2016;42:1-8. 
31. Wallner W, Sengenberger R, Strick R, Strissel PL, Meurer B, Beckmann MW, Schlembach D. Angiogenic growth factors in maternal and fetal serum in pregnancies complicated by intrauterine growth restriction. Clin Sci (Lond). 2007;112:51-7.

32. Borras D, Perales-Puchalt A, Ruiz Sacedon N, Perales A. Angiogenic growth factors in maternal and fetal serum in pregnancies complicated with intrauterine growth restriction. J Obstet Gynaecol. 2014;34:218-20.

33. Semczuk-Sikora A, Krzyzanowski A, Stachowicz N, Robak J, Kraczkowski J, Kwiatek M, Semczuk M. Maternal serum concentration of angiogenic factors: PIGF, VEGF and VEGFR-1 and placental volume in pregnancies complicated by intrauterine growth restriction. Ginekol Pol. 2007:78:783-6.

34. Kuhnel E, Kleff V, Stojanovska V, Kaiser S, Waldschutz R, Herse F, Plosch T, Winterhager E, Gellhaus A. Placental-specific overexpression of sFlt-1 alters trophoblast differentiation and nutrient transporter expression in an IUGR mouse model. J Cell Biochem. 2016;

35. Zamarian AC, Araujo Junior E, Daher S, Rolo LC, Moron AF, Nardozza LM. Evaluation of biochemical markers combined with uterine artery Doppler parameters in fetuses with growth restriction: a case-control study. Arch Gynecol Obstet. 2016;294:715-23.

36. Fadigas C, Peeva G, Mendez O, Poon LC, Nicolaides KH. Prediction of smallfor-gestational-age neonates: screening by placental growth factor and soluble fms-like tyrosine kinase-1 at 35-37 weeks. Ultrasound Obstet Gynecol. 2015;46:191-7.

37. Smith GC, Crossley JA, Aitken DA, Jenkins N, Lyall F, Cameron AD, Connor $\mathrm{JM}$, Dobbie R. Circulating angiogenic factors in early pregnancy and the risk of preeclampsia, intrauterine growth restriction, spontaneous preterm birth, and stillbirth. Obstet Gynecol. 2007;109:1316-24.

38. Crispi F, Llurba E, Dominguez C, Martin-Gallan P, Cabero L, Gratacos E. Predictive value of angiogenic factors and uterine artery Doppler for earlyversus late-onset pre-eclampsia and intrauterine growth restriction. Ultrasound Obstet Gynecol. 2008;31:303-9.

39. Schlembach D, Wallner W, Sengenberger R, Stiegler E, Mortl M, Beckmann MW, Lang U. Angiogenic growth factor levels in maternal and fetal blood: correlation with Doppler ultrasound parameters in pregnancies complicated by pre-eclampsia and intrauterine growth restriction. Ultrasound Obstet Gynecol. 2007;29:407-13.

40. Gaccioli F, Sovio U, Cook E, Hund M, Charnock-Jones DS, Smith GCS. Screening for fetal growth restriction using ultrasound and the sFLT1/PIGF ratio in nulliparous women: a prospective cohort study. The Lancet Child \& Adolescent Health. 2018;2:569-81.

41. Hernandez-Diaz S, Toh S, Cnattingius S. Risk of pre-eclampsia in first and subsequent pregnancies: prospective cohort study. Bmj. 2009;338:b2255.

42. Ananth CV, Keyes KM, Wapner RJ. Pre-eclampsia rates in the United States, 1980-2010: age-period-cohort analysis. Bmj. 2013;347:f6564.

43. Duley L. The global impact of pre-eclampsia and eclampsia. Semin Perinatol. 2009:33:130-7.

44. Gardosi J, Francis A. Adverse pregnancy outcome and association with small for gestational age birthweight by customized and population-based percentiles. Am J Obstet Gynecol. 2009;201 (28):e21-8.

Ready to submit your research? Choose BMC and benefit from:

- fast, convenient online submission

- thorough peer review by experienced researchers in your field

- rapid publication on acceptance

- support for research data, including large and complex data types

- gold Open Access which fosters wider collaboration and increased citations

- maximum visibility for your research: over $100 \mathrm{M}$ website views per year

At BMC, research is always in progress.

Learn more biomedcentral.com/submissions 